\title{
Bioenergy-induced land-use change emissions with sectorally fragmented policies
}

\section{Leon Merfort ( $\square$ leon.merfort@pik-potsdam.de)}

Potsdam Institute for Climate Impact Research https://orcid.org/0000-0003-1704-6892

\section{Nico Bauer}

Potsdam Institute for Climate Impact Research (PIK), Member of the Leibniz Association, Germany https://orcid.org/0000-0002-0211-4162

\section{Florian Humpenöder}

Potsdam Institute for Climate Impact Research https://orcid.org/0000-0003-2927-9407

\section{David Klein}

Pik-Potsdam

\section{Jessica Strefler}

Potsdam Institute for Climate Impact Research https://orcid.org/0000-0002-5279-4629

\section{Alexander Popp}

Potsdam Institute for Climate Impact Research

\section{Gunnar Luderer}

Potsdam Institute for Climate Impact Research https://orcid.org/0000-0002-9057-6155

\section{Elmar Kriegler}

Potsdam Institute for Climate Impact Research https://orcid.org/0000-0002-3307-2647

\section{Article}

Keywords: land-use emission policies, climate policy, bioenergy production

Posted Date: May 19th, 2021

DOl: https://doi.org/10.21203/rs.3.rs-404716/v1

License: (c) (i) This work is licensed under a Creative Commons Attribution 4.0 International License. Read Full License 


\section{Bioenergy-induced land-use change}

\section{emissions with sectorally fragmented}

\section{policies}

Authors: Leon Merfort*,a, Nico Bauer ${ }^{\mathrm{a}}$, Florian Humpenöder ${ }^{\mathrm{a}}$, David Klein ${ }^{\mathrm{a}}$, Jessica Strefler ${ }^{\mathrm{a}}$, Alexander Popp $^{a}$, Gunnar Luderera, ${ }^{a, b}$ Elmar Kriegler ${ }^{a, c}$

\section{Affiliations:}

apotsdam Institute for Climate Impact Research (PIK), Member of the Leibniz Association, Germany

${ }^{\mathrm{b}}$ Technical University of Berlin, Germany

'University of Potsdam, Germany

PIK- Potsdam Institute for Climate Impact Research

Telegraphenberg A 31, 14473 Potsdam

Postal address: P.O. Box 6012 03, 14412 Potsdam

Technical University of Berlin

Straße des 17. Juni 135

10623 Berlin 


\section{University of Potsdam}

Am Neuen Palais 10, House 9

14469 Potsdam

*Corresponding author

Email: leon.merfort@pik-potsdam.de

Phone: +49 33128820783 


\section{Abstract}

2 We assess the impact of different land-use emission policies within a broader climate policy framework on

3 bioenergy production and associated land-use carbon emissions. We use the global Integrated Assessment

4 Model REMIND-MAgPIE integrating the energy and land-use sectors and derive alternative climate change

5 mitigation scenarios over the $21^{\text {st }}$ century. If $\mathrm{CO}_{2}$ emissions are regulated consistently across sectors, land-

6 use change emissions of biofuels are limited to $12 \mathrm{kgCO}_{2} / \mathrm{GJ}$. Without land-use emission regulations

7 applied, bioenergy-induced emissions increase substantially and the emission factor per energy unit raises

8 to levels slightly below diesel combustion $\left(64 \mathrm{~kg} \mathrm{CO}_{2} / \mathrm{GJ}\right)$. Pricing these emissions on the level of bioenergy

9 consumption diminishes bioenergy deployment and the associated $\mathrm{CO}_{2}$ emissions, while failing to reduce

10 the average emission factor. Despite effective reduction of land-use emissions, undifferentiated

11 penalization of bioenergy use substantially increases mitigation costs. If supply side policies

12 comprehensively regulate direct and indirect emissions, bioenergy can be produced much more

13 sustainably.

14 Main

\section{Introduction}

16 To limit global mean temperature and to achieve the Paris climate targets, society needs to bring down

17 global carbon emissions to net zero and strongly reduce non- $\mathrm{CO}_{2}$ emissions ${ }^{1}$. Future cost-effective climate

18 change mitigation strategies often rely on large-scale bioenergy deployment ${ }^{2}$. The use of biofuels provides

19 a low carbon alternative to fossil fuel-based liquids as well as the possibility to enable carbon dioxide

20 removal from the atmosphere using bioenergy with carbon capture and storage (BECCS) ${ }^{3}$. The combined

21 ability of biofuels to overcome and compensate for decarbonization bottlenecks is a major driver of its

22 future large-scale deployment ${ }^{4-6}$. However, the relevance of bioenergy as a means to climate change

23 mitigation is also controversially discussed ${ }^{7-9}$, since its production will be in competition with other land- 
use (LU) activities and thus increases the already existing pressure on land-systems ${ }^{10,11}$. For example, largescale bioenergy production can threaten biosphere integrity and biogeochemical flows, might increase unsustainable freshwater use and may also lead to higher food prices ${ }^{11-13}$. Bioenergy also has substantially higher specific land requirements than other renewable energy sources ${ }^{14}$. There is thus a risk that the growing demand and willingness to pay for bioenergy induced by strengthened climate protection measures hits a land-use sector that is already under pressure today ${ }^{12,15}$. In addition, there is the threat

30 that direct and indirect land-use change ${ }^{16,17}$ (LUC/iLUC) $\mathrm{CO}_{2}$ emissions associated with bioenergy 31 production can largely offset abated emissions ${ }^{18,19}$.

32 A broad range of studies has investigated LUC and iLUC emissions induced by bioenergy production at different locations. They have identified vastly different emission factors (EF) ranging from 0 to $100 \mathrm{~kg} \mathrm{CO}_{2} / \mathrm{GJ}_{\text {biofuel }^{20-23}}$, which might be even higher than for oil derived diesel $\left(74 \mathrm{~kg} \mathrm{CO}_{2} / \mathrm{GJ}^{24}\right)$. This broad uncertainty reflects the heterogeneity of land types ${ }^{23}$ - characterized by stored carbon content and crop yield rates - and the flexibility of land-use and initial land conditions ${ }^{25,26}$. Yet, these studies do not reflect the interplay between future global climate policies and the allocation of land areas for bioenergy and

38 food production. Given that stringent climate policies are projected to be the main driver for bioenergy 39 production ${ }^{4}$, however, it is crucial to link the assessment of EFs to the future transformation pathways of 40 the energy-system. Our study assesses bioenergy EFs under a range of alternative climate change 41 mitigation policies and thereby closes this gap in the literature.

42 Most studies analyzing global climate change mitigation pathways using Integrated Assessment Models 43 (IAM) consider, among others, the benchmark of an idealized climate policy framework putting a uniform 44 carbon equivalent price on greenhouse gas (GHG) emissions from all sectors, sources and countries ${ }^{9}$. This 45 is an effective policy to avoid carbon emissions from the land-use sector due to bioenergy production. 46 However, in the current real-world situation, energy- and land-use policies are regionally and sectorally 47 fragmented. While many countries already started to implement GHG emission pricing in the energy 
sector, institutional capacity building is much less developed in the agricultural and forestry sector ${ }^{27}$. The already high challenges in implementing carbon pricing in the energy system give an indication of the difficulties in pricing emissions from the land-use sector. Here additional technical and in particular governance challenges related to monitoring, reporting and verification (MRV) need to be overcome. It is also debated whether GHG prices should be the same in the energy and land-use sector, given differences

53 in abatement cost curves and distributional impacts ${ }^{28-30}$. The implicit assumption in IAMs of institutional 54 feasibility of LU mitigation has been criticized $^{31}$, since fragmented or even completely absent LU-based GHG regulatory schemes can lead to substantial emission leakage from regulated to unregulated regions $^{32,33}$ or sectors ${ }^{18,34,35}$ involving excess bioenergy production, both factors counteracting mitigation efforts. Since LU-based regulatory schemes are hard to implement on a globally comprehensive level (i.e. on the supply side), there has been the proposal to regulate bioenergy consumption directly via import controls, volume caps or by attributing EFs to bioenergy - in particular biofuels (e.g. as part of EU directives $\left.{ }^{36}\right)$. While there have been studies analyzing auxiliary policy frameworks apart from a uniform carbon price ${ }^{37,38}$, none of them systematically compared the effectiveness of LU-based regulator schemes, which may be weak or fragmented, with demand-side controls on bioenergy deployment in terms of EFs related to bioenergy production and its land-use displacement effects.

By comparing the effectiveness of different bioenergy demand- and supply-side policies to reduce the EF of bioenergy in climate change mitigation scenarios, we aim to answer the following research questions:

(1) If comprehensive LU-based regulation is not available, how effective can direct regulation of bioenergy deployment be in harnessing bioenergy while limiting its adverse impacts?

(2) To what extent would only weak and fragmented LU regulation be able to limit the adverse impacts of bioenergy deployment?

(3) How do different policy assumptions affect the level of carbon pricing necessary in the energy sector to achieve the Paris climate target? 
73 We apply the IAM framework REMIND-MAgPIE ${ }^{4,39,40}$ to derive climate change mitigation pathways that are

74 compatible with limiting warming to $2^{\circ} \mathrm{C}$ by setting a carbon budget of $1000 \mathrm{Gt} \mathrm{CO}_{2}$ to total energy- and

75 LU-based $\mathrm{CO}_{2}$ emissions from 2018 to $2100^{41}$. Key socio-economic assumptions on population, GDP,

76 dietary choices and energy demand projections that drive the model results reflect a middle-of-the-road

77 scenario (Shared Socioeconomic Pathway $2(\mathrm{SSP} 2))^{42}$. The coupling of the energy-system model

78 REMIND ${ }^{43,44}$ with the LU model MAgPIE ${ }^{45,46}$ allows for the analysis of feedback effects between bioenergy

79 demand, production and associated LUC emissions. By comparing these pathways with a counterfactual

80 scenario without bioenergy available for decarbonizing the energy sector, we extract the pure impact of

81 bioenergy production on total and specific LUC emissions and on the mitigation strategies of the energy

82 sector as well as on macro-economic costs. Specific emissions are thus calculated ex-post and we express

83 the emission factor $\mathrm{EF}_{\text {ex-post }}$ in terms of $\mathrm{kg} \mathrm{CO}_{2}$ emitted per $\mathrm{GJ}$ of biofuel produced.

\section{Policy Design (detailed description in methods section)}

85 While all scenarios reach the same climate target by imposing a uniform price on GHGs in the energy

86 sector, they differ with respect to assumptions on bioenergy and LU-related policies (given in Table 1),

87 implying different carbon price levels.

88 There are two benchmark policy assumptions, between which the different alternative approaches unfold.

89 The scenario with a globally Uniform Carbon equivalent Price (UCP) in the energy- and LU sector marks the

90 first best policy option to comply with the climate policy target reaching a carbon price of $147 \$ / \mathrm{t} \mathrm{CO} 2$ in

91 2050. This policy is contrasted with a scenario where the LU sector is lacking any regulatory scheme for

92 controlling emissions (noLUreg), i.e. there is neither a price instrument on any type of land-use based GHG

93 emissions nor any widespread land-protection scheme. The 2050 carbon price here reaches a much higher

94 level of $291 \$ / \mathrm{tCO}_{2}$. 
95 As a first set of alternative supply-side policies we gradually explore the effect of different levels of 96 fragmentation between energy- and LU sector. This is represented by reduced GHG price levels on LU 97 sector-based emissions of $10-50 \%$ compared to the price on emissions from the energy sector 98 (LUprice10\%-50\%). Alongside these price-based supply-side policies we explore the efficacy of various 99 land-protection schemes, namely forest protection (protForest, protPrimforest), and the protection of 100 distinct focus areas (protBH, protCPD, protFF, and protLW).

101 Contrasted to supply-side policies that are difficult to implement at global scale, we examine how a 102 demand-side tax on bioenergy consumption can reduce LUC emissions. We analyze the effect of different 103 bioenergy tax levels, representing the uncertainty of potential bioenergy EFs (bioTax10-50, c.f. Table 1 for 104 a description of the tax levels). In addition, we explore scenarios, in which we impose a ban on bioenergy 105 imports on top of the different bioenergy tax levels (bioTaxNolmp10-50), since a considerable amount of 106 biomass can be consumed in regions other than the one where it is produced ${ }^{47}$. In particular, exports from 107 tropical regions with high carbon stocks might promote additional LUC. 


\begin{tabular}{|c|c|}
\hline Scenario & Policy design \\
\hline \multicolumn{2}{|c|}{ Benchmark policies } \\
\hline UCP & Globally uniform* carbon price across energy- and land-use-sector \\
\hline noLUreg & Globally uniform carbon price only within the energy sector; No regulation of land-use GHG emissions \\
\hline \multicolumn{2}{|c|}{ Supply-side policies } \\
\hline LUprice10-50\% & $\begin{array}{l}\text { Globally uniform carbon price within the energy sector; Globally uniform carbon price within the land- } \\
\text { use sector at a level of } 10-50 \% \text { of the price in the energy system }\end{array}$ \\
\hline protForest & Globally uniform carbon price only within the energy sector; Primary and secondary forests are protected \\
\hline protPrimforest & Globally uniform carbon price only within the energy sector; Primary forests are protected \\
\hline protBH & Globally uniform carbon price only within the energy sector; Biodiversity Hotspots are protected \\
\hline protCPD & Globally uniform carbon price only within the energy sector; Centers of Plant Diversity are protected \\
\hline protFF & Globally uniform carbon price only within the energy sector; Frontier Forests are protected \\
\hline protLW & Globally uniform carbon price only within the energy sector; Last of the Wild areas are protected \\
\hline \multicolumn{2}{|c|}{ Demand-side policies } \\
\hline bioTax10-50 & $\begin{array}{l}\text { Globally uniform carbon price only within the energy sector; No regulation of land-use GHG emissions; } \\
\text { Additionally bioenergy consumption is charged with a tax. The tax level is determined by the carbon price } \\
\text { multiplied with a predefined, fixed factor given in } \mathrm{kgCO}_{2} \text { per } \mathrm{GJ} \mathrm{JE}_{\mathrm{PE}} \text { of primary energy ("PE") dry matter } \\
\text { biomass. E.g. bioTax } 20 \text { stands for a policy charging bioenergy as if it had an EF of } 20 \mathrm{kgCO}_{2} / \mathrm{GJ} \mathrm{PE} \text {. Due to } \\
\text { conversion losses } 10-50 \mathrm{kgCO}_{2} / \mathrm{GJ} \text { PE correspond to } 24-122 \mathrm{kgCO} 2 / \mathrm{GJ} \text { biofuel and while the tax level is } \\
\text { expressed in units of primary energy, ex-post EFs are expressed in units of biofuel for a better } \\
\text { comparability with other values from the literature. }\end{array}$ \\
\hline $\begin{array}{l}\text { bioTaxNolmp10- } \\
50\end{array}$ & $\begin{array}{l}\text { Globally uniform carbon price only within the energy sector; No regulation of land-use emissions; a } \\
\text { Additionally a tax on bioenergy consumption of bioenergy as above; Bioenergy imports are prohibited }\end{array}$ \\
\hline
\end{tabular}

Table 1/Policy Design. Scenarios are divided into the two benchmark scenarios (UCP and noLUreg), scenarios with supply-side

113 In the absence of restrictions on land-use emissions (noLUreg) cumulative (2020 to 2100) bioenergy114 induced LUC emissions increase more than ten-fold from $44 \mathrm{Gt} \mathrm{CO}_{2}$ in the UCP case to $493 \mathrm{Gt} \mathrm{CO}_{2}$ (Fig. 115 1a). This is qualitatively similar but quantitatively more muted compared with Wise et al. ${ }^{18}$ Since global 116 bioenergy production only doubles to $236 \mathrm{EJ} / \mathrm{yr}, \mathrm{EF}_{\text {ex-post }}$ on an 80 year time horizon increases from $12 \mathrm{~kg}$ $117 \mathrm{CO}_{2} / \mathrm{GJ}_{\text {biofuel }}$ to $64 \mathrm{~kg} \mathrm{CO} / \mathrm{GJ}_{\text {biofuel, }}$ which is only slightly smaller than the $\mathrm{EF}$ of diesel (Fig. $1 \mathrm{~b}$ ).

118 In between these benchmark scenarios supply-side and demand-side policies lead to different 119 consequences for bioenergy and LUC emissions. While even a small fraction of the energy systems' carbon 120 price level applied to terrestrial GHG emissions (LUprice20\%) is sufficient to reduce $\mathrm{EF}_{\text {ex-post }}$ to $12133 \mathrm{~kg} \mathrm{CO} / \mathrm{GJ}_{\text {biofuel, }}$ a demand-side tax on bioenergy consumption is not affecting the specific average 122 emissions attributed to a unit of bioenergy, since emissions only decline as a consequence of reduced 

thus LUC emissions only to a small extend. precise areas that are removed from the land-pool available for bioenergy production and other agricultural activities. While a policy protecting all forests resembles the UCP case to a large extend emissions and EFs from unregulated levels.
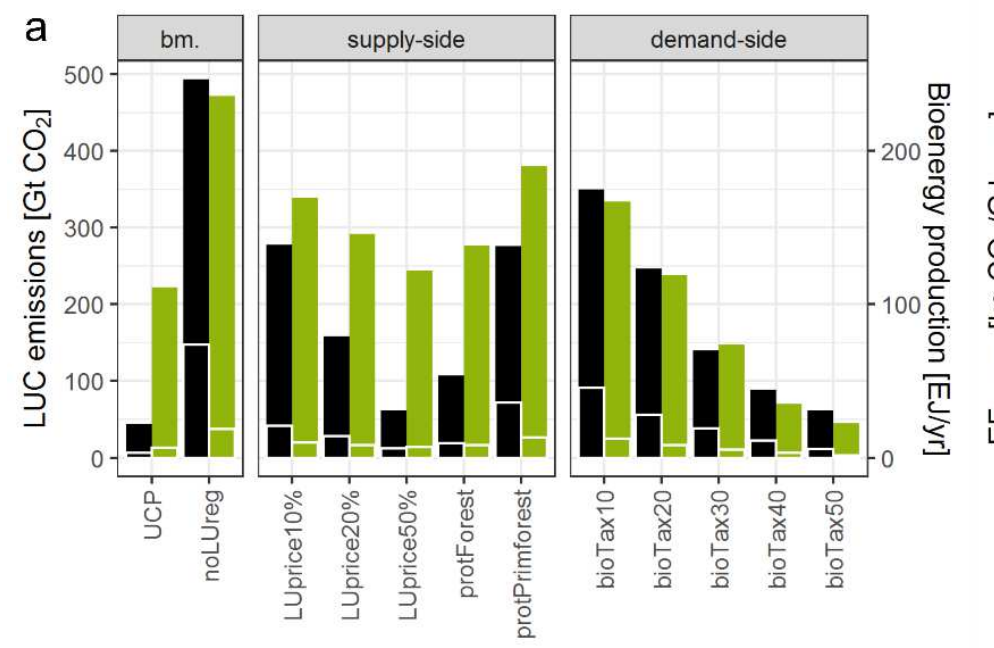

Total bioenergy-induced LUC emissions (left scale) Averaged bioenergy production (right scale)

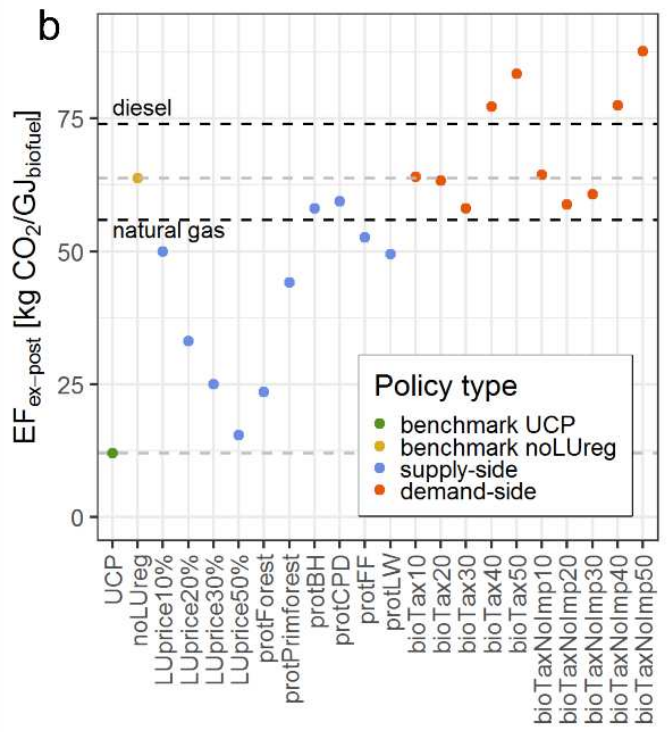

Fig. 1 | Bioenergy-induced LUC emissions, bioenergy production and emission factors. (a) Emissions, given as the total global LUC emissions and bioenergy, given as the averaged annual global production, are both evaluated for period from 2020 to 2100 and shown for different policy settings. Besides the two benchmark scenarios ("bm."), policies are grouped into "supply-side" and 
141 Regarding the effect of distinct policies, we generally observe a considerable disconnect between the 142 spatial patterns of bioenergy production and LUC emissions. We find that - irrespective of the policy design

143 - a large fraction of LUC emissions does not originate from the land areas of bioenergy cultivation, but 144 occurs indirectly at formerly forested areas or pasture, where agricultural activity displaced by bioenergy 145 production is moved to (see Fig. 2). Those iLUC emissions as well as bioenergy plantations directly replacing 146 carbon-rich ecosystems contribute to high emissions factors (as for example in the northern regions of 147 South America for noLUreg, see Fig. 2 a,c,d). Without supply-side policies globally more than $85 \%$ of 148 additional emissions induced by bioenergy production originate from territories that together only 149 generate less than $16 \%$ of total biomass production (red and dark red wedges in Fig. 2 b). By contrast, the 150 main part of the bioenergy (more than three quarters across all policy settings) is being produced with a 151 direct emission factor of less than $37 \mathrm{~kg} \mathrm{CO}_{2} / \mathrm{GJ}_{\text {biofuel }}$ (half the $\mathrm{EF}$ of diesel, blue wedges in Fig 2.), directly 152 causing less than $10 \%$ of the total bioenergy-induced emissions if LU regulation policies are absent. 153 Therefore, by only accounting for direct LUC emissions within major bioenergy producing regions, only a small fraction of attached emissions can be traced. Accordingly, the total iLUC emissions related to the total bioenergy production are considerable and vary strongly with the regulatory framework.

This leads to two conclusions. First, the high flexibility of the LU sector in reallocating agricultural uses makes iLUC emissions hard to avoid, although the absolute level depends on the underlying global LU regulatory framework. Second, previous studies analyzing the direct LUC EF of bioenergy often suggested that increasing bioenergy production is linked to increasing EF, implying that limiting bioenergy production can also effectively limit EF (e.g. Daioglou et $\mathrm{al}^{23}$ ). This rests on the assumption that expanding agricultural area due to bioenergy use proceeds along the lines of least marginal EF of land conversion. However, while such an allocation would be optimal from a sustainability perspective it is not the allocation that emerges 
164 choices. As a consequence of this, a demand-side bioenergy tax reducing the overall consumption of 165 energy crops does not automatically lead to sparing areas with high carbon stocks, as the allocation of 166 emissions by EFs is not affected by the tax (compare noLUreg and bioTax10, Fig. 2 b). 

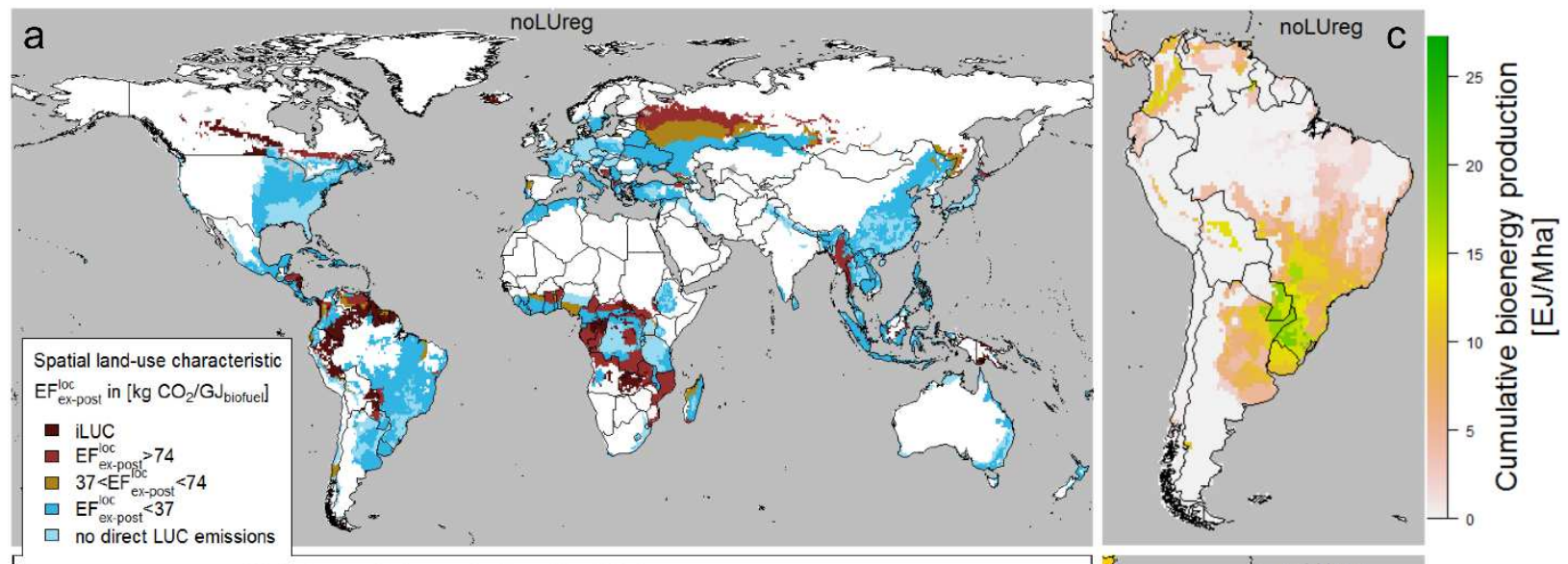

b

Global cumulative emissions $\left[\mathrm{Gt} \mathrm{CO}_{2}\right]$

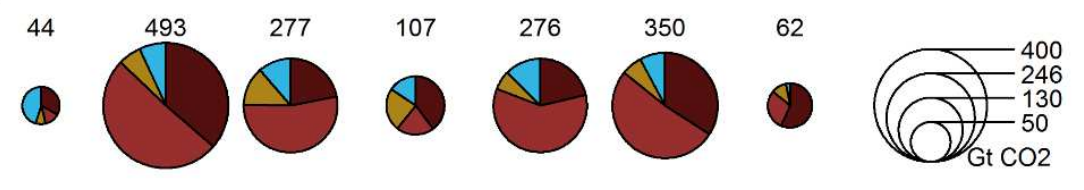

Global averaged bioenergy production $[\mathrm{EJ} / \mathrm{yr}]$
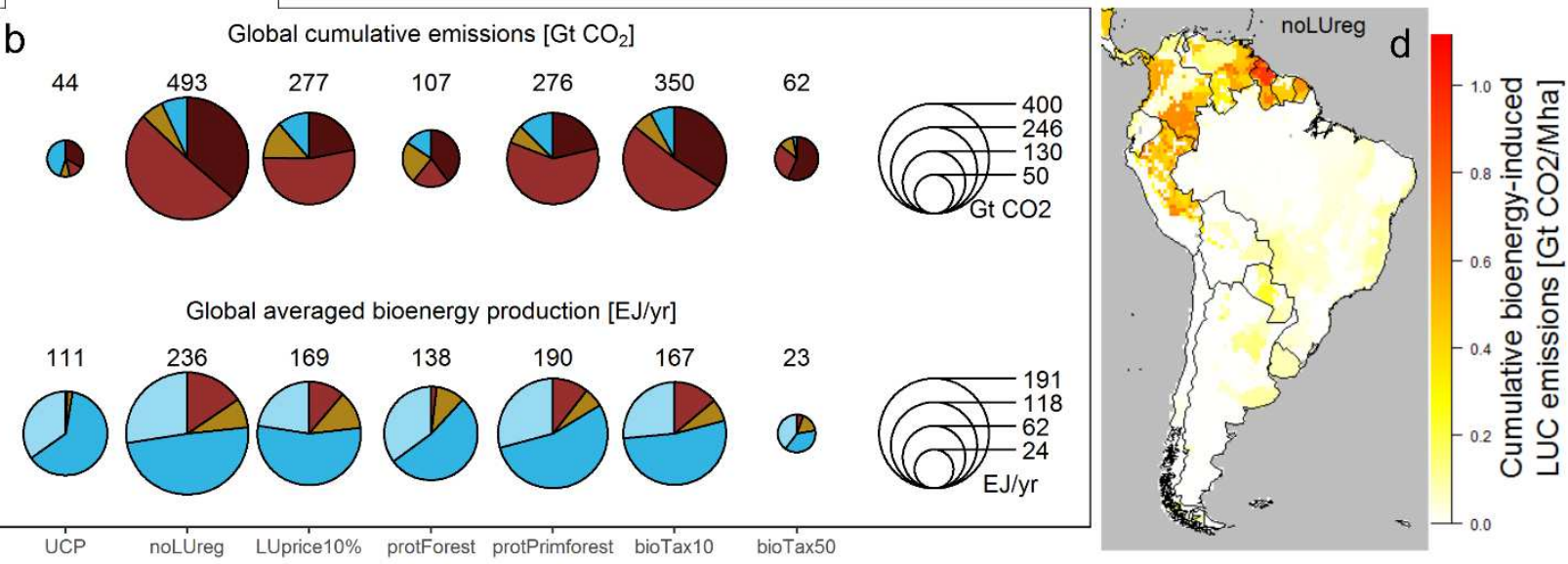

Fig. 2/ Spatial allocation of $\mathrm{LUC} \mathrm{CO}_{2}$ emissions and bioenergy production. Panel (a) shows a spatially disaggregated map of bioenergy EFs that emerge in the absence of LU regulation (noLUreg). There are territories, where bioenergy is being produced without additional LUC emissions at the place of production (bright blue areas). Here bioenergy is either being produced on marginal or abandoned land or on land, where it displaces other agricultural activities. On the other hand, natural vegetation can be converted to agricultural land to balance the production of agricultural goods that were displaced by bioenergy (dark red areas,

173 iLUC emissions). Other territories are classified by EF

174 production (for reference, $74 \mathrm{~kg} \mathrm{CO}_{2} / \mathrm{GJ}$ is the EF of diese ${ }^{24}$ ). In panel (b) the sizes of the pie charts reflect the total global

175 bioenergy-induced LUC emissions and the global averaged annual bioenery production, respectively, for different policy

176 assumptions (other scenarios are shown in Fig. S5, SI). The sizes of the wedges reflect the amount of emissions and bioenergy production and are color-coded according to the associated EFs as described in (a). Panels (c) and (d) show the spatial distribution of bioenergy production and bioenergy-induced emissions, respectively, for the example of South America. In all four panels quantities are cumulated over the period between 2020 and 2100. See methods section for a description of the analysis of EF $F_{e x-p o s t}$ and the SI for figures of the other policy assumptions, including maps of baseline (not bioenergy-related) emissions. 
182

183
Regarding the composition of total cumulated $\mathrm{CO}_{2}$ emissions, we observe vastly different allocations of the carbon budget for the varying policy assumptions. While cumulated emissions induced by bioenergy production up until 2100 will be offset by deploying carbon removal using BECCS and direct air capture with carbon storage (DACCS) technologies (Fig. 3a), in in the absence of comprehensive LU sector emission regulations a large fraction of BECCS removals will be offset by the additional LUC emissions (Fig. 3b). For instance, if regulations only comprise incomplete land protection schemes or a bioenergy demand-side tax, LUC emissions are relatively high in relation to the bioenergy production reflected by the high emission factor (44 to over $60 \mathrm{~kg} \mathrm{CO}_{2} / \mathrm{GJ}_{\text {biofuel }}$ ). In such a regulatory framework, carbon removal by BECCS is largely used to offset these emissions. Hence, due to the heterogeneity and flexibility of the LU sector, incomplete regulation of the additional emissions caused by biomass production implies that bioenergy is not necessarily carbon negative, if combined with CCS (or at least only with a poor efficacy), but rather only carbon neutral. Without LU mitigation, only $15 \%$ of carbon dioxide removal from BECCS remain. Before 2050 cumulated bioenergy-induced LUC emissions even exceed BECCS savings by far for all policy settings except for a uniform carbon price (Fig. S6, SI). Note that this only compares LUC emissions with carbon removal, but does not account for fossil fuel substitution.

In comparison to the UCP policy, we furthermore observe that cumulated energy system emissions need to be reduced in scenarios with high LUC emissions to balance the total budget. The additional biomass is then used to accelerate the phase out of fossil fuels, particularly oil (Fig. S7, SI).

If bioenergy is priced on the demand-side in the range of LUC emissions caused on the supply-side, LUC emissions decrease with increasing tax level, but the reduced demand for bioenergy enforces a stronger and faster electrification in comparison to both the UCP and the noLUreg scenario (Fig. S8, SI). At the same time the share of emissions from the transport sector increases due to the lack of biofuels. The dwindling 
204 availability of biomass even leads to higher $\mathrm{CO}_{2}$ prices (Fig. 3c) compared to the already high prices in 205 noLUreg, which makes DACCS competitive as a means to compensate for residual emissions.

206 It is also worth noting that even a comparatively small carbon price on LU-sector-based emissions 207 (LUprice10\%) is sufficient to abate most of the non-bioenergy-related $\mathrm{LUC} \mathrm{CO}_{2}$ emissions (from 235 in 208 noLUreg to $56 \mathrm{Gt} \mathrm{CO}_{2}$ ). At the same time, the required carbon price is reduced by $35 \%$ from 291 to $193 \$ / \mathrm{t}$ $209 \mathrm{CO}_{2}$ in 2050 (Fig. 3c). 

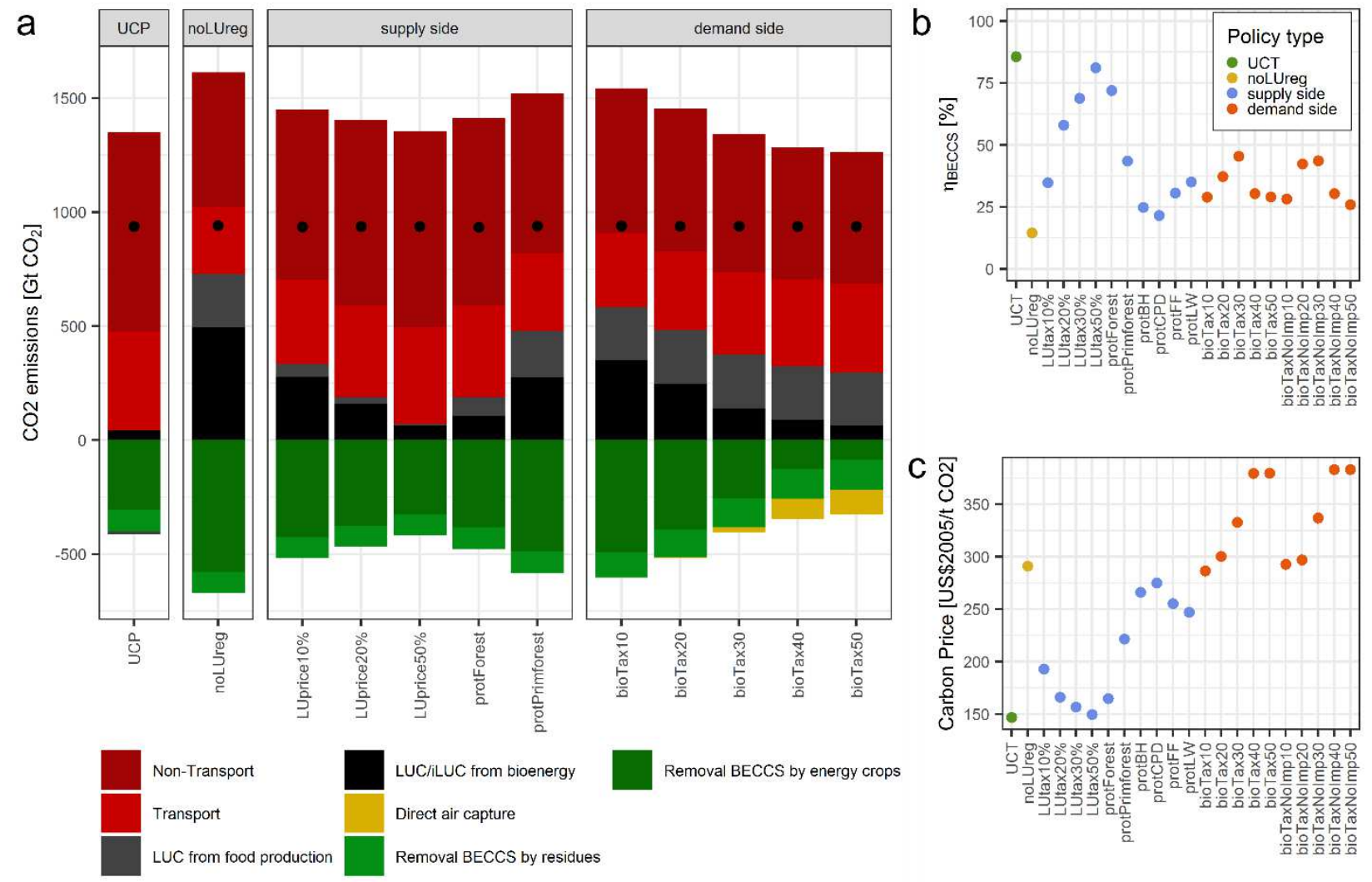

211 Fig. 3/ Composition emissions, BECCS efficiency and carbon prices. (a) Composition of total anthropogenic $\mathrm{CO}_{2}$ emissions, given

212 for different policy assumptions cumulated from 2020 until 2100. Black dots refer to the net totals. LUC emissions not related to

213 bioenergy production comprise $\mathrm{CO}_{2}$ LUC emission from all other agricultural activities. Bioenergy from residues is assumed to be

214 carbon neutral. For the calculation of the shares please refer to the methods section. Composition of the other scenarios are shown

215 in Fig. S2, in the SI. (b) The BECCS efficiency factor $\eta_{B E C C S}$ is an indicator of how much of the sequestered carbon is virtually removed

216 from the atmosphere if bioenergy-induced LUC emissions are subtracted. For instance, $\eta_{B E C C S}=15 \%$ for noLUreg implies that

217 only 15\% of the CDR savings are effectively removed from the atmosphere, as the remaing $85 \%$ are offset by LUC emissions.

218 (c) Shown are energy system GHG prices in the year 2050. After a phase in period, prices are equal across regions from 2050 on.

\section{Discussion and conclusion}

220 In our study we analyzed the impact of bioenergy on LUC emissions in different climate policy settings,

221 comparing supply-side measures controlling land-use allocation with demand-side measures controlling

222 bioenergy use. We showed that in a scenario, where climate policy creates a large demand for bioenergy,

223 the specific emissions attributed to a unit of bioenergy produced can be lowered by supply-side emissions 
224 regulations in the land use sector. Regulations of bioenergy demand reduce deployment level, but fail to 225 induce a reduction of EF, thus resulting in substantially higher overall mitigation effort and carbon prices 226 to reach climate targets. For instance, increasing the price on terrestrial carbon can decrease the EF, while 227 a bioenergy tax on consumption only reduces the total bioenergy quantity, keeping the EF virtually 228 constant at a high level. A demand-side bioenergy tax fails to steer LUC decisions towards areas with low 229 EF and is not suitable to emulate the uniform carbon price regime across all sectors.

230 In order to fully capture the impact on direct and indirect land use emissions in the absence of direct 231 regulation of land use, a demand-side bioenergy tax would need to be applied to approximately $23225 \mathrm{~kg} \mathrm{CO}_{2} / \mathrm{GJ}$ PE at the primary energy level ( $61 \mathrm{~kg} \mathrm{CO}_{2} / \mathrm{GJ}_{\text {biofuel }}$ with $41 \%$ conversion efficiency), in order to 233 value fossil and terrestrial emissions equally on a 80-year time horizon. Computed on a shorter time 234 horizon, the EF to be applied is substantially higher ( $200 \mathrm{~kg} \mathrm{CO}_{2} / \mathrm{GJ}_{\text {biofuel }}$ if evaluated until 2050 , see Fig. $235 \mathrm{~S} 3, \mathrm{SI}$ ), since most emissions occur upfront, while by far the largest part of the bioenergy is being produced 236 after 2050. This EF for biofuels is even higher than values identified in dedicated studies, which are mostly 237 found to be less than $100 \mathrm{~kg} \mathrm{CO}_{2} / \mathrm{GJ}_{\mathrm{PE}}$ on a 30 -year time horizon ${ }^{21}$ for biofuels from thermo-chemical 238 conversion.

239 On the supply side, however, implementing a land-use emission carbon price of only $20 \%$ of the price in 240 the energy-system (33\$/t CO $\mathrm{CO}_{2}$ in 2050$)$ eliminates almost half the bioenergy-induced LUC emissions. A full 241 forest protection scheme is also effective, while conserving only specific land-types is not sufficient due to 242 the flexibility to move agricultural activities ${ }^{35}$. In combination with the ineffectiveness of demand-side 243 measures to reduce the EF of bioenergy, this is a strong argument for a direct regulation of all LU-sector244 based emission fluxes as a means to mitigate bioenergy-related LUC emissions. This is in particular 245 compelling, since GHG emissions associated with overall food production need to be reduced substantially 246 to achieve the $1.5^{\circ}$ or well below $2^{\circ} \operatorname{target}^{48}$. It is important to note that the focus of this study was purely 247 on $\mathrm{CO}_{2}$ LUC emissions. To assess the whole value of bioenergy for climate change mitigation strategies 
248 (including also e.g. $\mathrm{N}_{2} \mathrm{O}$ emissions from fertilization of bioenergy crops $^{49}$ ), other adverse side effects (such 249 as unsustainable freshwater use or higher food prices) but also benefits from fossil fuel substitution need 250 to be considered as well.

251 Our study confirms that LUC emission pricing is an effective and efficient instrument to regulate LUC 252 emissions even under large-scale deployment of bioenergy. However, we also show that those policies 253 cannot be emulated by demand-side regulation of bioenergy use, raising the question to what extent the 254 land-use sector can be effectively regulated to make large-scale bioenergy use sustainable. The literature 255 points to numerous challenges for regulating land use, ranging from MRV to the need for huge institutional 256 capacity ${ }^{50-52}$. Moreover, the distributional implications of regulating land-use emissions affect land tenure 257 and livelihoods, raising strong equity and political economy concerns ${ }^{28,29}$. Hence, the policy challenge is to 258 either comprehensively regulate the LU sector and produce biomass at scale or reduce bioenergy demand. 259 The main driving force behind this challenge is the huge demand for non-electric energy, particularly 260 transport fuels. Thus, broad and deep electrification of end-uses would lower the pressure on the land261 system and bypass the regulatory gaps in the land-use sector ${ }^{53}$. 
General. To assess the impact of bioenergy and to fully cover feedback effects between $\mathrm{LUCCO}_{2}$ emissions

264 and bioenergy-demand, we use the coupled integrated assessment modeling framework REMIND265 MAgPIE.

266 REMIND 2.1.2 is an open source global multi-regional Ramsey-type general equilibrium model of economic

267 growth with a detailed representation of the energy sector, hard-coupled to the macro-economic core ${ }^{43,44}$.

268 Using optimization methods, it finds a market equilibrium while maximizing intertemporal global welfare.

269 Via different conversion routes REMIND represents the supply, trade and conversion of biomass

270 feedstocks along the value chain to final energy carriers along with relevant GHG emissions and removals.

271 Therefore, the REMIND model values the energy and the carbon content of biomass feedstocks given the

272 market conditions and the regulatory framework. In climate change mitigation scenarios most of the

273 biomass is converted into bio-liquids.

274 MAgPIE v4.2.1 is an open source global multi-regional partial equilibrium model of the land-use sector that

275 models land-use dynamics spatially explicitly using recursive dynamic optimization ${ }^{45,46}$. The model covers

276 two types of modern ( $2^{\text {nd }}$ generation) bioenergy production, namely grassy and woody biomass. Since

277 irrigation of bioenergy crops leads to unsustainable freshwater use ${ }^{11}$, we only allowed for rain fed 278 production.

279 Both models are soft-coupled, balancing prices and quantities of bioenergy feedstocks and GHGs ${ }^{4}$. The 280 main policy instrument to meet a given climate target is a pricing of GHG emissions. GHG prices that are 281 by default applied to all types of GHGs from all sectors and sources are derived in REMIND and passed to 282 MAgPIE so as to meet the predefined GHG budget in 2100 of total energy- and LU-sector based $\mathrm{CO}_{2}$ 283 emissions. All scenarios in this study are derived with middle of the road assumptions on socioeconomic 284 drivers (SSP2) and meet a global $\mathrm{CO}_{2}$ emissions budget of $1000 \mathrm{Gt} \mathrm{CO}_{2}$ to total energy- and LU-based $\mathrm{CO}_{2}$ 
emissions from 2018 to 2100 , allowing for a temporary overshoot. This budget is derived by subtracting $100 \mathrm{Gt} \mathrm{CO}_{2}$ emissions due to earth system feedback from the remaining carbon budget of 1170 given in Rogelj et al. ${ }^{41}\left(67^{\text {th }}\right.$ percentile for the $2^{\circ} \mathrm{C}$ target), arriving at $1070 \mathrm{Gt} \mathrm{CO}_{2}$. As safety margin, this value is rounded down to $1000 \mathrm{Gt} \mathrm{CO}_{2}$.

Carbon prices. In the UCP scenario all types of GHG emissions from the energy and the LU sector are charged with a uniform carbon equivalent price $P_{\mathrm{GHG}}(t, r)$ in $\left[\$ / \mathrm{CO}_{2}\right]$ that is increasing with time $t$. Prices can differ between modeling regions $r$ before 2050 for reasons of inter-regional equity, but they will eventually converge to a globally harmonized prices until $2050^{39}$. In scenarios with a partial LU price (LUprice10\%-50\%) the price on GHG emissions in the LU sector is reduced for every time step and every modeling region to the corresponding fraction of the respective price level on energy system related GHG emissions (e.g. to $10 \%)$.

In order to be consistent with the narrative of a largely unregulated Agriculture, Forestry and Other Land Use sector (AFOLU), we assumed that in scenarios without a price on $\mathrm{CO}_{2}$ emissions from LUC (noLUreg, protForest, protPrimforest, protBH, protCPD, protFF, protLW and bioTax scenarios) also non- $\mathrm{CO}_{2} \mathrm{GHGs}_{\text {are }}$ exempted from the GHG price in the LU sector. This has the side-effect that these scenarios also involve substantially higher non- $\mathrm{CO}_{2}$ GHG emissions from agricultural activities compared to scenarios with a carbon price, in particular $\mathrm{CH}_{4}$ and $\mathrm{N}_{2} \mathrm{O}$. As a result, radiative forcing levels and resulting global mean temperature responses can differ between scenarios, even though cumulative $\mathrm{CO}_{2}$ emissions coincide. However, since agricultural $\mathrm{CH}_{4}$ emissions are not related to bioenergy production and $\mathrm{N}_{2} \mathrm{O}$ emissions from grassy bioenergy production are negligible compared to $\mathrm{LUC} \mathrm{CO}_{2}$ emissions (see Fig. S4, $\mathrm{SI}$, for a comparison), we omit the effect of non- $\mathrm{CO}_{2}$ GHG emissions for assessing the impact of bioenergy. Nevertheless, differences between scenarios in global mean temperature in 2100 as a result of varying LUS16, SI). 
Land protection. In scenarios with explicit land-protection schemes (protForest, protPrimforest, protBH,

$310 \operatorname{prot} C P D, \operatorname{prot} F F, \operatorname{prot} L W)$ we removed the respective areas from the land-pool that is potentially available

311 for any agricultural activities. In Fig. S9 - Fig. S14 in the SI, the protected areas are depicted. protForest is

312 a scenario in which all primary and secondary forests are protected, which is a total area of 3683 Mha,

313 while in protPrimforest only primary forests with a total area of 1339 Mha are removed from the land-

314 pool. The other land-protection policies only affect some focus areas. In protBH Biodiversity Hotspots, in protCPD Centers of Plant Diversity, in protFF Frontier Forests and in prot $L$ W Last Wild areas are protected ${ }^{55}$.

These focus areas cover areas of 909, 651, 1084 and 3635 Mha respectively.

Additionally, in all scenarios specific land areas are protected or dedicated for afforestation according to climate agreement.

Bioenergy tax. As explained above, the default policy assumption regarding the pricing of emissions is a uniform carbon price on both energy- and LU-based GHG emissions. Emissions related to bioenergyproduction are thus already penalized directly within the LU sector, which is why the energy system by default treats bioenergy as a carbon neutral energy carrier. In the scenarios with demand-side policies (bioTax) we assign an ex-ante emission factor $\left(E F_{\text {ex-ante }}\right)$ to bioenergy that should reflect potential bioenergy-related GHG emissions on a global average. $E F_{\text {ex-ante }}$ represents emissions on a global average and is equal for each economic region $r$ and time step $t$. It directly transforms into a bioenergy $\operatorname{tax} T_{\text {bio }}(t, r)$ via the price on $\mathrm{GHGs} P_{\mathrm{GHG}}(t, r)$

$$
T_{\mathrm{bio}}(t, r)=E F_{\text {ex-ante }} \cdot P_{\mathrm{GHG}}(t, r) \quad[\$ / \mathrm{GJ} \mathrm{PE}]
$$
literature and the results of the present study indicate that specific emissions attributed to a unit of bioenergy are highly uncertain even on a global average, we explore the effect of different values of 
333 conversion efficiency). It is worth noting that $E F_{\text {ex-ante }}$ is in general not equal to the actual emissions that

334 are eventually attributed to bioenergy and which are derived ex-post from our scenarios ( $\left.E F_{\text {ex-post }}\right)$.

335 Please also note that in most other publications applying the REMIND model bioenergy is actually charged

336 with a "sustainability tax" that reduces the demand for bioenergy irrespective of the policy design to

337 reflect uncovered externalities, such as unsustainable water usage, food price increase, the loss of

338 biodiversity and nitrogen losses to the environment ${ }^{39}$. In the present study, however, we deactivated this

339 tax, since we wanted to assess the impact of bioenergy given a certain policy assumption in an otherwise

340 uncontrolled market.

341 Ex-post emission factor. Due to iLUC induced by bioenergy production it is intrinsically impossible to

342 disentangle $\mathrm{LUCCO}_{2}$ emissions related to bioenergy production from $\mathrm{LUC}$ emissions that result from other

343 agricultural activities such as an expansion of crop land or pasture. For each policy setting $p$ we therefore

344 first derive a counterfactual scenario that depicts a world, in which purpose grown bioenergy production

345 is not allowed (bioOff) - a similar approach has been applied for example in Daioglou et al. ${ }^{23}$ and Pehl et

346 al. ${ }^{19}$ By comparing the actual policy run, in which bioenergy production is activated (bioOn), with this

347 counterfactual scenario, we can reveal the effect that bioenergy has on the coupled energy-LU-system for

348 a given policy assumption $p$. The ex-post emission factor comprising all $\mathrm{LUC} \mathrm{CO}_{2}$ emissions attributed to

349 bioenergy production is then given by

350

$$
E F_{\text {ex-post }}(p)=\frac{E_{\text {bioOn }}(p)-E_{\text {bioOff }}(p)}{B_{\text {bioOn }}(p)} \quad\left[\mathrm{kg} \mathrm{CO}_{2} / \mathrm{GJ}\right]
$$

351 where $E_{\mathrm{bioOn}}$ and $E_{\mathrm{bioOff}}$ are the total LUC emissions that emerge over the period from 2020 to 2100 for 352 the scenario with bioenergy on and off, respectively. $B_{\text {bioon }}$ is the total amount of purpose grown 353 lignocellulosic biomass produced globally over the same period. Please note that while $E F_{\text {ex-post }}$ is usually 354 expressed in terms of $\mathrm{CO}_{2}$ emissions per unit of biofuel, to make it comparable with fossil fuels, the 355 thermo-chemical conversion to liquid fuels is subject to substantial conversion losses (the energy 
357 carriers derived from biomass, in particular electricity or hydrogen, exhibit different emission factors due 358 to different energy conversion efficiencies.

EFs are also evaluated spatially disaggregated. For our study the LU model MAgPIE was applied using 1000 distinct simulation units $r_{\mathrm{MAgPIE}}$ revealing individual patterns of agricultural activities. Each simulation unit represents a cluster of aggregated 0.5-degree resolution grid cells with similar properties ${ }^{45,56}$ (see Fig. S15, SI) and for each of them an EF can be calculated individually:

$$
E F_{\text {ex-post }}^{\text {loc }}\left(p, r_{\text {MAgPIE }}\right)=\frac{E_{\text {bioOn }}\left(p, r_{\text {MAgPIE }}\right)-E_{\text {bioOff }}\left(p, r_{\text {MAgPIE }}\right)}{B_{\text {bioOn }}\left(p, r_{\text {MAgPIE }}\right)}\left[\mathrm{kg} \mathrm{CO}_{2} / \mathrm{GJ}\right]
$$

364 There are clusters of grid cells without bioenergy production $\left(E F_{\mathrm{ex} \text {-post }}^{\mathrm{loc}}=\infty\right)$, and others, for which the difference in emissions to the counterfactual scenario is zero or even marginally negative, i.e. a simulation unit $r_{\text {MAgPIE }}$ with equal or less emissions than in the scenario without bioenergy. Here the $E F_{\text {ex-post }}^{\text {local }}$ is set to zero.

Please note that, since the EFs are given as the ratio of emissions and bioenergy production, there is no information on the total volume of each of these quantities in the different areas in Fig. 2a. The spatial allocation of LUC emission and bioenergy production quantities is depicted in section "Spatial land-use 371 characteristics" of the SI.

372 It is also important to again highlight that EFs result from a comparison with a counterfactual scenario, in 373 which bioenergy is not used. This approach can lead to a situation, in which additional LUC emissions to 374 the counterfactual scenario are rather small, while baseline LUC emissions from the counterfactual 375 scenario (in the same simulation unit) are already substantial. Bioenergy production is then associated 376 with a relatively small $E F_{\text {ex-post, }}^{\text {loc }}$ even though the actually occurring emissions are large. However, since 
377 these emissions also emerge in the baseline/counterfactual scenario, in this study they are not attributed 378 to bioenergy.

379 The BECCS efficiency factor. We defined the efficiency of the CDR potential of BECCS by

$$
\eta_{\mathrm{BECCS}}=\left(1-\frac{E_{\mathrm{bioOn}}-E_{\mathrm{bioOff}}}{C D R_{\mathrm{BECCS}, \text { bioOn }}}\right) \times 100 \%
$$

381 where $C D R_{\mathrm{BECCS}, \text { bioOn }}$ are all negative emissions associated with BECCS from purpose grown biomass. A 382 scenario without bioenergy-induced LUC would thus imply an efficiency of $100 \%$, while in a scenario, in 383 which bioenergy-related emissions are equal to the CDR saving via BECCS, the efficiency is $0 \%$.

384 Since bioenergy from residues is allowed in the counterfactual scenarios, we excluded the BECCS emission 385 savings related to residues from the calculation of $\eta_{\mathrm{BECCS}}$. Please note that this efficiency factor is derived 386 to relate bioenergy-induced LUC emissions to the CDR potential of BECCS. It does, however, not cover other benefits of bioenergy to the energy system, particularly the benefits of substituting fossil fuels by biofuels. On the other hand bioenergy related emissions do not cover all negative effects, as described in 389 the paragraph on the bioenergy tax.

\section{Acknowledgements}

392 The research leading to these results has received funding from the German Federal Ministry of

393 Education and Research (BMBF, grant number 01LA1809A, DIPOL project).

\section{Author contributions}

395 Leon Merfort performed model experiments, analyzed the scenarios, produced the figures, and lead the writing of the manuscript. Leon Merfort, Nico Bauer, Florian Humpenöder, Gunnar Luderer and Elmar

397 Kriegler designed the study, the scenarios and the analysis. All authors contributed to the development of 398 the models, the presented ideas, and to the text. 


\section{Competing interests}

400 The authors declare no competing interests.

\section{Code and data availability}

402 REMIND is open source and available on GitHub. The model version used in this study is 2.1.2, which can 403 be downloaded at https://github.com/remindmodel/remind/releases/tag/v2.1.2.

404 MAgPIE is open source and available on GitHub. The model version used in this study is 4.2.1, which can 405 be downloaded at https://github.com/magpiemodel/magpie/releases/tag/v4.2.1. Documentation can be 406 found at https://rse.pik-potsdam.de/doc/magpie/4.2.1/.

407 The results of the scenarios shown in this paper will be archived at Zenodo upon publication of this 408 paper.

409

410 References

411 1. Allen, M. et al. Summary for Policymakers. In: Global Warming of $1.5^{\circ} \mathrm{C}$ an IPCC special report. (2018).

412 2. Bauer, N. et al. Global energy sector emission reductions and bioenergy use: overview of the

413 bioenergy demand phase of the EMF-33 model comparison. Climatic Change (2018)

414 doi:10.1007/s10584-018-2226-y.

415 3. Klein, D. et al. The value of bioenergy in low stabilization scenarios: an assessment using REMIND-

416 MAgPIE. Climatic Change 123, 705-718 (2014).

417 4. Bauer, N. et al. Bio-energy and $\mathrm{CO} 2$ emission reductions: an integrated land-use and energy sector 418 perspective. Climatic Change (2020) doi:10.1007/s10584-020-02895-z.

419 5. Rose, S. K. et al. Bioenergy in energy transformation and climate management. Climatic Change 123, $420 \quad 477-493$ (2014).

421 6. Krey, V., Luderer, G., Clarke, L. \& Kriegler, E. Getting from here to there - energy technology 422 transformation pathways in the EMF27 scenarios. Climatic Change 123, 369-382 (2014). 
423

424

425

426

427

428

429

430

431

432

433

434

7. Jia, G. et al. Land-climate interactions. in Climate Change and Land: an IPCC special report on climate change, desertification, land degradation, sustainable land management, food security, and greenhouse gas fluxes in terrestrial ecosystems (eds. Shukla, P. R., Skea, J., Calvo Buendia, E. \& Masson-Delmotte, V.) (In press).

8. IPCC. Special Report on climate change, desertification, land degradation, sustainable land management, food security, and greenhouse gas fluxes in terrestrial ecosystems (SRCCL). (2019).

9. Creutzig, F. et al. Reconciling top-down and bottom-up modelling on future bioenergy deployment. Nature Clim Change 2, 320-327 (2012).

10. Popp, A. et al. The economic potential of bioenergy for climate change mitigation with special attention given to implications for the land system. Environ. Res. Lett. 6, 034017 (2011).

11. Humpenöder, F. et al. Large-scale bioenergy production: how to resolve sustainability trade-offs? Environ. Res. Lett. 13, 024011 (2018).

12. Heck, V., Gerten, D., Lucht, W. \& Popp, A. Biomass-based negative emissions difficult to reconcile with planetary boundaries. Nature Clim Change 8, 151-155 (2018).

13. Hof, C. et al. Bioenergy cropland expansion may offset positive effects of climate change mitigation for global vertebrate diversity. PNAS 115, 13294-13299 (2018).

14. Luderer, G. et al. Environmental co-benefits and adverse side-effects of alternative power sector decarbonization strategies. Nat Commun 10, 5229 (2019).

15. Gerten, D. et al. Feeding ten billion people is possible within four terrestrial planetary boundaries. Nature Sustainability 3, 200-208 (2020).

16. Verstegen, J. A. et al. What can and can't we say about indirect land-use change in Brazil using an integrated economic - land-use change model? GCB Bioenergy 8, 561-578 (2016).

17. Arima, E. Y., Richards, P., Walker, R. \& Caldas, M. M. Statistical confirmation of indirect land use change in the Brazilian Amazon. Environ. Res. Lett. 6, 024010 (2011). 
18. Wise, M. et al. Implications of Limiting $\mathrm{CO} 2$ Concentrations for Land Use and Energy. Science 324,

$448 \quad 1183-1186(2009)$.

19. Pehl, M. et al. Understanding future emissions from low-carbon power systems by integration of 450 life-cycle assessment and integrated energy modelling. Nature Energy 2, 939-945 (2017).

451 20. Daioglou, V. et al. Progress and barriers in understanding and preventing indirect land-use 452 change. Biofuels, Bioproducts and Biorefining 14, 924-934 (2020).

453 21. Warner, E., Zhang, Y., Inman, D. \& Heath, G. Challenges in the estimation of greenhouse gas 454 emissions from biofuel-induced global land-use change. Biofuels, Bioproducts and Biorefining 8, 114455125 (2014).

456 22. Wicke, B., Verweij, P., Meijl, H. van, Vuuren, D. P. van \& Faaij, A. P. Indirect land use change: 457 review of existing models and strategies for mitigation. Biofuels 3, 87-100 (2012).

458 23. Daioglou, V. et al. Greenhouse gas emission curves for advanced biofuel supply chains. Nature $459 \quad$ Clim Change 7, 920-924 (2017).

460 24. Redaktionsassistenz 2, U. B. A. CO2-Emissionsfaktoren für fossile Brennstoffe.

$461 \quad$ (Umweltbundesamt, 2016).

462 25. Wicke, B., Dornburg, V., Junginger, M. \& Faaij, A. Different palm oil production systems for 463 energy purposes and their greenhouse gas implications. Biomass and Bioenergy 32, 1322-1337 464 (2008).

465 26. Creutzig, F. et al. Bioenergy and climate change mitigation: an assessment. GCB Bioenergy 7, $466916-944(2015)$

467 27. World Bank. State and Trends of Carbon Pricing 2020.

468 https://openknowledge.worldbank.org/handle/10986/33809 (2020).

469 28. Stevanović, M. et al. Mitigation Strategies for Greenhouse Gas Emissions from Agriculture and $470 \quad$ Land-Use Change: Consequences for Food Prices. Environ. Sci. Technol. 51, 365-374 (2017). 
471 29. Hasegawa, T. et al. Risk of increased food insecurity under stringent global climate change 472 mitigation policy. Nature Climate Change 8, 699-703 (2018).

473 30. Fujimori, S. et al. A multi-model assessment of food security implications of climate change 474 mitigation. Nature Sustainability 2, 386-396 (2019).

475 31. Creutzig, F. Economic and ecological views on climate change mitigation with bioenergy and 476 negative emissions. GCB Bioenergy 8, 4-10 (2016).

477 32. Otto, S. A. C. et al. Impact of fragmented emission reduction regimes on the energy market and 478 on $\mathrm{CO} 2$ emissions related to land use: A case study with China and the European Union as first 479 movers. Technological Forecasting and Social Change 90, Part A, 220-229 (2015).

480 33. González-Eguino, M., Capellán-Pérez, I., Arto, I., Ansuategi, A. \& Markandya, A. Industrial and 481

34. Reilly, J. et al. Using Land To Mitigate Climate Change: Hitting the Target, Recognizing the Trade-

35. Popp, A. et al. Land-use protection for climate change mitigation. Nature Climate Change 4, $485 \quad$ 1095-1098 (2014).

486 36. Directive (EU) 2018/2001 of the European Parliament and of the Council of 11 December 2018 on 487 the promotion of the use of energy from renewable sources (Text with EEA relevance.). 328 vol. OJ L $488 \quad$ (2018).

489 37. Calvin, K. et al. Trade-offs of different land and bioenergy policies on the path to achieving $490 \quad$ climate targets. Climatic Change 123, 691-704 (2014).

38. Calvin, K. et al. Near-term limits to mitigation: Challenges arising from contrary mitigation effects 492 from indirect land-use change and sulfur emissions. Energy Economics 42, 233-239 (2014).

493 39. Kriegler, E. et al. Fossil-fueled development (SSP5): An energy and resource intensive scenario 494 for the 21st century. Global Environmental Change 42, 297-315 (2017). 
495

496

497

498

40. Bauer, N. et al. Quantification of an efficiency-sovereignty trade-off in climate policy. Nature 588, 261-266 (2020).

41. Rogelj, J. et al. Mitigation Pathways Compatible with $1.5^{\circ} \mathrm{C}$ in the Context of Sustainable Development. 82.

42. Riahi, K. et al. The Shared Socioeconomic Pathways and their energy, land use, and greenhouse gas emissions implications: An overview. Global Environmental Change 42, 153-168 (2017).

43. Baumstark, L., Luderer, G. \& Kriegler, E. REMIND2.1: Transformation and innovation dynamics of the energy-economic system within climate and sustainability limit. (in preparation).

44. Luderer, G. et al. REMIND - REgional Model of INvestments and Development. (Zenodo, 2020). doi:10.5281/zenodo.4091409.

45. Dietrich, J. P. et al. MAgPIE 4 - a modular open-source framework for modeling global land systems. Geoscientific Model Development 12, 1299-1317 (2019).

46. Dietrich, Jan Philipp et al. MAgPIE - An Open Source land-use modeling framework. (Zenodo, 2020). doi:10.5281/ZENODO.1418752.

47. Daioglou, V. et al. Implications of climate change mitigation strategies on international bioenergy trade. Climatic Change (2020) doi:10.1007/s10584-020-02877-1.

48. Clark, M. A. et al. Global food system emissions could preclude achieving the $1.5^{\circ}$ and $2^{\circ} \mathrm{C}$ climate change targets. Science 370, 705-708 (2020).

49. Popp, A. et al. On sustainability of bioenergy production: Integrating co-emissions from agricultural intensification. Biomass and Bioenergy 35, 4770-4780 (2011).

50. Ochieng, R. M., Visseren-Hamakers, I. J., Arts, B., Brockhaus, M. \& Herold, M. Institutional effectiveness of REDD+ MRV: Countries progress in implementing technical guidelines and good governance requirements. Environmental Science \& Policy 61, 42-52 (2016).

51. Wang, X. et al. Taking account of governance: Implications for land-use dynamics, food prices, and trade patterns. Ecological Economics 122, 12-24 (2016). 
520 52. Waller, L. et al. Contested framings of greenhouse gas removal and its feasibility: Social and 521 political dimensions. WIREs Climate Change 11, e649 (2020).

522 53. Luderer, G. et al. Accelerated electrification based on cheap renewables facilitates reaching Paris 523 Climate targets. Nat Energy 20 (in review).

$52454 . \quad$ Meinshausen, M., Wigley, T. M. L. \& Raper, S. C. B. Emulating atmosphere-ocean and carbon 525 cycle models with a simpler model, MAGICC6 - Part 2: Applications. Atmospheric Chemistry and 526 Physics 11, 1457-1471 (2011).

527 55. Kreidenweis, U. et al. Pasture intensification is insufficient to relieve pressure on conservation 528 priority areas in open agricultural markets. Glob Change Biol 24, 3199-3213 (2018).

$52956 . \quad$ Dietrich, J. P., Popp, A. \& Lotze-Campen, H. Reducing the loss of information and gaining 530 accuracy with clustering methods in a global land-use model. Ecological Modelling 263, 233-243 531 (2013).

532 57. Pachauri, R. K. et al. Climate Change 2014: Synthesis Report. Contribution of Working Groups I, II 533 and III to the Fifth Assessment Report of the Intergovernmental Panel on Climate Change. (IPCC, 534 2014). 


\section{Supplementary Files}

This is a list of supplementary files associated with this preprint. Click to download.

- BioenergyinducedlandusechangeemissionswithsectorallyfragmentedpoliciesSI.pdf 